\title{
Preferências alimentares no ambiente escolar ${ }^{1}$
}

\author{
Mariana Schievano Danelon²; Maria Conceição Pereira da Fonseca ${ }^{3}$; Marina Vieira da \\ Silva ${ }^{2}$
}

Na totalidade das escolas públicas de ensino infantil e fundamental do Brasil está presente o Programa Nacional de Alimentação Escolar - PNAE e, em expressiva parcela das unidades, encontram-se disponíveis as cantinas/lanchonetes escolares. A presença destes dois serviços nas unidades de ensino possivelmente traz dificuldades para que os alunos selecionem os alimentos da dieta. O estudo teve por objetivo identificar as preferências alimentares de crianças e adolescentes no ambiente escolar, analisando a influência do convívio do PNAE e das cantinas sobre o comportamento alimentar dos estudantes. Para tanto, foram realizadas entrevistas, utilizando-se de formulário especificamente elaborado, junto a 324 escolares (com idade entre 6 e 14 anos) de seis unidades públicas de Campinas (SP). Os resultados revelaram que 75\% dos alunos aderiam ao PNAE, sendo que 38,3\% participavam freqüentemente (entre quatro e cinco dias por semana). A aceitação dos alunos às preparações do cardápio do PNAE esteve diretamente associada com a frequiência de adesão ao programa. As preparações do cardápio apresentaram maior aceitabilidade entre os alunos de menor idade e não foram observadas diferenças quanto à aceitação das preparações e os rendimentos familiares per capita. As refeições salgadas do tipo prato único e as sopas foram as menos selecionadas para integrar o cardápio do PNAE. Cerca de $76 \%$ dos alunos aderiam à cantina, sendo que maior proporção $(63,8 \%)$ adquiria alimentos esporadicamente (até dois dias por semana). A adesão à cantina foi mais freqüente entre as meninas e entre os alunos com maiores rendimentos. Quanto à convivência dos serviços escolares, observou-se tanto uma relação de complementaridade quanto de substituição da merenda escolar em relação aos alimentos comercializados na cantina. Evidenciou-se a necessidade de orientação, para que os alunos optem de forma consciente pelos alimentos disponíveis nas escolas.

Palavras-chave: cantinas escolares, alimentação escolar, preferências alimentares, Programa Nacional de Alimentação Escolar

\section{Students' food preferences}

In all of the Brazilian elementary public schools the Brazilian School Meal Program - PNAE is present and, in an expressive share of the learning units, school canteens/cafeterias are available. The presence of both these services at schools possibly makes students' food choices more difficult. This paper is aimed at identifying children and adolescents' food preferences in the school environment, analyzing the influence of the coexistence of PNAE and cafeterias on the students' food behavior. For so, interviews were conducted, using tailored questionnaires, with 324 students (aged between 6 and 14), enrolled in six public learning units in Campinas, São Paulo State. It was verified that $75.0 \%$ of the schoolchildren consumed the meals provided

\footnotetext{
${ }^{1}$ Artigo elaborado a partir da dissertação de M.S.DANELON, intitulada "Estado nutricional, consumo alimentar e estilo de vida de escolares de Campinas - SP". Departamento de Agroindústria, Alimentos e Nutrição, Escola Superior de Agricultura "Luiz de Queiroz", Universidade de São Paulo; 2007.

${ }^{2}$ ESALQ/USP.

${ }^{3}$ IMS, Campus Anísio Teixeira/UFBA
} 
by the PNAE, being 38.3\% effective eaters (between four and five days a week). The acceptance of students to the meals from the PNAE was directly associated with the frequency of participation in the program. The school meals presented more acceptability between young pupils and there were not observed differences between school meals' acceptance and per capita family incomes. The 'plate of the day' salty meals (like risotto and pasta) and soups were the least chosen meals by schoolchildren to compose the menus from the PNAE. Circa $76 \%$ of the students adhered to the school cafeterias, and the highest proportion (63.8\%) bought food sporadically (up to two days a week). The adherence to the cafeteria was more frequent between girls and pupils from higher family incomes. Regarding the coexistence of school food services, it was observed both a complementary relation and a replacement for the school meals in relation to foods sold by school cafeterias. It was possible to see the need of nutritional education programs so that students can choose, in a conscious way, the food available at the school food services.

Keywords: food preferences, Brazilian School Meal Program, school cafeterias, school meals

\section{Introdução}

Além da família, primordial grupo de referência dos indivíduos na maioria das sociedades para a formação de hábitos saudáveis [1], a escola, principal centro de ensino-aprendizagem no qual as crianças e adolescentes permanecem por expressivo período de tempo diário, deveria desempenhar importante papel na consolidação de comportamentos relacionados à saúde e nutrição. É fundamental que a escola promova a educação nutricional e propicie condições para a vivência dos conceitos da área de nutrição [2].

Nesse contexto, merecem destaque os serviços de alimentação disponíveis nas unidades de ensino: o Programa Nacional de Alimentação Escolar - PNAE, presente na totalidade das escolas públicas de ensino infantil e fundamental do país, e as cantinas/lanchonetes, freqüentemente presentes nas unidades, como serviços aos quais poderiam ser incorporadas estratégias para a promoção de uma alimentação adequada do ponto de vista nutricional.

O PNAE, que vigora no Brasil há mais de meio século, visa suplementar, por meio da distribuição gratuita de alimentos/refeições, durante o intervalo das atividades escolares, com no mínimo $15 \%$ das necessidades nutricionais diárias (e no mínimo 30\% das necessidades para creches, escolas indígenas e de áreas remanescentes de quilombos) a alimentação dos alunos, matriculados na educação infantil (creches e pré-escolas), no ensino fundamental da rede pública e em escolas mantidas por entidades filantrópicas. Entre os objetivos delineados para o programa encontra-se, também, a formação de bons hábitos alimentares [3,4].

Em 2006, o programa atendeu cerca de 36,3 milhões de alunos, com investimentos da ordem de $\mathrm{R} \$ 1,48$ bilhões [5], sendo coordenado nacionalmente pelo Fundo Nacional de Desenvolvimento da Educação FNDE, do Ministério da Educação e do Desporto - MEC, órgão responsável, de forma parcial, pelos custos do programa relativos à aquisição de gêneros. Para a composição dos cardápios do PNAE, 70\% dos recursos do programa devem ser utilizados para a aquisição de alimentos básicos, respeitando-se os hábitos alimentares e a vocação agrícola de cada localidade, devendo ser planejados de modo a atender às necessidades nutricionais dos beneficiários do programa, considerandose os custos e demais recursos disponíveis [4].

Uma das principais formas de avaliação do desempenho do PNAE refere-se à análise de indicadores junto aos beneficiários do programa, como a adesão e a aceitabilidade às refeições que, por sua vez, dependem da realização de diagnósticos relativos às preferências dos alunos [6].

Particularmente no caso do Programa Nacional de Alimentação Escolar operacionalizado no município de Campinas denominado, no presente artigo, de Programa de Alimentação Escolar - PAE de Campinas, registra-se que, desde a sua municipalização em 1984, passou por alterações no modelo de gerenciamento, incluindo a autogestão (19841996), a terceirização do serviço (1997-2000) 
e a gestão compartilhada (vigente desde 2001) - esta última caracterizada por convênio entre a Secretaria Municipal de Educação do município e as Centrais de Abastecimento de Campinas S/A - CEASA [7,8]. Tais modificações na gestão do programa promoveram mudanças no que diz respeito à operacionalização do PAE e à elaboração dos cardápios distribuídos, sendo introduzida, desde o início do período da gestão compartilhada, maior variedade de produtos in natura, favorecida pela parceria com a CEASA [9]. Essas alterações possivelmente causaram impacto na adesão dos alunos e na sua aceitação às refeições distribuídas pelo programa. Estudos que identifiquem as preferências dos escolares no que se refere ao PAE de Campinas, particularmente após o período da gestão compartilhada, são escassos.

Em expressiva parcela das unidades de ensino brasileiras encontram-se disponíveis os serviços das cantinas escolares. Nesses locais, as crianças e os adolescentes possuem a oportunidade de selecionar, de acordo com o poder aquisitivo, preferências e hábitos, os alimentos que serão adquiridos. A presença desse tipo de serviço, concomitantemente à distribuição gratuita de refeições pelo PNAE, possivelmente gera dificuldades para que os escolares selecionem de forma adequada os alimentos que devem integrar as pautas alimentares [2], ressaltando-se que os fatores que motivam os alunos a optar por um serviço nas unidades de ensino ainda foram pouco estudados.

Face ao exposto, o presente trabalho teve como objetivo identificar as preferências alimentares de crianças e adolescentes no ambiente escolar, analisando-se alguns dos condicionantes para a escolha dos alimentos pelos alunos. Também se buscou avaliar a influência do convívio do Programa de Alimentação Escolar - PAE e das cantinas sobre o comportamento alimentar dos estudantes.

\section{Metodologia}

O estudo integrou projeto financiado pelo Conselho Nacional de Desenvolvimento 68
Científico e Tecnológico - CNPq (processo $\mathrm{N}^{\mathrm{o}}$ 504369/2003-2), intitulado "Contrastes regionais nos custos, qualidade e operacionalização do Programa Nacional de Alimentação Escolar - PNAE e seu impacto sobre os padrões alimentares da população brasileira", desenvolvido durante o período de 2004 a 2006, envolvendo amostra oriunda de municípios pertencentes aos Estados de São Paulo (Campinas, Piedade e Piracicaba), Paraná (Toledo) e Rio de Janeiro (Seropédica), com o objetivo de implementar análises que subsidiassem políticas/programas, especialmente no contexto da segurança alimentar e nutricional, por meio da análise dos padrões alimentares da população brasileira e da sua interface com o maior programa de suplementação alimentar em vigor no Brasil - o Programa Nacional de Alimentação Escolar - PNAE.

Nesse contexto, o presente estudo foi desenvolvido no município de Campinas (SP), durante os meses de setembro a novembro de 2004. O projeto da pesquisa foi submetido ao Comitê de Ética em Pesquisa da Faculdade de Odontologia de Piracicaba (SP), Universidade Estadual de Campinas e aprovado (protocolo № 099/2004) em 2004.

A definição da amostragem das unidades de ensino que integrariam a pesquisa seguiu o delineamento do projeto principal, no qual se estabeleceu, para cada município integrante da pesquisa financiada pelo $\mathrm{CNPq}$, o número de seis escolas públicas de ensino fundamental. Esse número foi definido com base nas informações sobre o sistema de ensino de cada município, disponibilizadas no Censo Educacional de 2004 [10], no tempo necessário para a coleta de dados e nos recursos humanos e econômicos disponíveis para a realização da pesquisa. Trata-se, portanto, de uma amostra de conveniência, que possibilitou o alcance da totalidade dos objetivos.

Para a seleção das unidades de ensino, empregou-se programa especificamente elaborado, no qual a probabilidade de uma escola ser sorteada foi proporcional ao seu número de alunos. Para isso, foi elaborada tabela acumulando-se o número de alunos, de maneira que cada escola ficava associada a um 
intervalo de valores de freqüência acumulada de estudantes. Sendo $N$ o número total de alunos de todas as escolas consideradas no município, foi gerado um número aleatório inteiro de 1 a $N$, todos com igual probabilidade. Em seguida, verificou-se qual era a escola cujo intervalo de freqüência acumulada incluía esse número inteiro obtido. Esta escola passou a integrar a amostra. Novos números foram gerados até completar o número previamente estabelecido $(n=6)$ de escolas da amostra, localizadas em regiões urbanas do município.

A partir da seleção das unidades de ensino $(n=6)$, foram sorteados três alunos com idade entre 6 e 14 anos de cada classe, das existentes na escola integrante da amostra. Visando-se assegurar o total de três alunos de cada classe ao final do processo, inicialmente foram entregues os Termos de Consentimento Livre e Esclarecido (TCLE) aos pais ou responsáveis por seis escolares. No caso da devolução de mais de três documentos (TCLE) com a aquiescência dos pais/responsáveis, novo sorteio foi realizado, selecionando-se apenas três escolares para permanecerem na amostra. A amostragem final foi composta por 324 escolares $(61,7 \%$ meninas e $38,3 \%$ meninos), de seis unidades públicas do município de Campinas (SP), sendo 40,1\% com idade entre 6 e 10 anos e a maioria $(59,9 \%)$ com idade entre 11 e 14 anos.

As informações sobre o consumo de alimentos no ambiente escolar foram obtidas por meio de entrevistas junto aos alunos, empregando-se formulário especificamente elaborado e pré-testado em unidade pública do município de Piracicaba (SP), não integrante da amostra da pesquisa.

O formulário adotado, do tipo semiaberto, continha questões que visavam à identificação da adesão (avaliada por meio da proporção de alunos que afirmaram consumir os alimentos/refeições) e da freqüência de adesão (identificada por meio do número de dias por semana que o aluno costumava consumir a alimentação) ao Programa de Alimentação Escolar - PAE, aos serviços das cantinas ou à aquisição de alimentos de outros locais para serem consumidos na escola.
Entre aqueles alunos que afirmaram aderir ao PAE, foi questionada a opinião relativa às preparações do cardápio do programa. Foram elaboradas análises de associação tendo por base a opinião dos alunos acerca das preparações distribuídas pelo PAE e variáveis, tais como idade dos escolares e a condição socioeconômica (identificada por meio da renda familiar per capita).

Integrava o formulário utilizado nas entrevistas uma questão na qual se solicitava aos alunos que selecionassem, entre doze opções pré-estabelecidas, cinco refeições que compusessem um cardápio do PAE. As opções, definidas com base em dados coletados previamente em etapa de pré-teste dos instrumentos, nos municípios que compunham o projeto principal na qual esta pesquisa estava inserida, foram divididas em seis categorias: almoço (composto por arroz, feijão, guarnição, hortaliças e fruta), lanche com suco (pão com queijo ou com patê e suco de fruta), sopa, prato único (composto pelas preparações "macarronada à bolonhesa" ou "risoto de frango"), doce (creme de chocolate ou arroz doce) e lanche com leite (leite com chocolate e bolo ou leite batido com frutas e biscoito), sendo permitido ao aluno repetir as preparações para a composição do cardápio teórico. Os resultados foram expressos em proporção de aceitação.

As informações sobre a adesão à cantina foram obtidas junto aos alunos de metade $(n=3)$ das unidades de ensino da amostra, que contavam com este tipo de serviço. Foram elaboradas análises de associação entre a adesão e a freqüência de adesão às cantinas e as variáveis: gênero, idade e estado nutricional dos alunos, além daquelas que refletem, em parte, a condição socioeconômica das famílias dos estudantes, como a renda familiar per capita e a escolaridade materna.

$\mathrm{O}$ estado nutricional dos alunos foi identificado por meio de avaliação antropométrica, adotando-se procedimentos recomendados pela World Health Organization [11]. Empregando-se o software Epi - Info 2000 [12], foi organizado um banco de dados, visando à elaboração dos cálculos $\mathrm{e}$ 
análise do Índice de Massa Corporal - IMC. Utilizou-se, como referência, o padrão antropométrico do Center for Disease Control and Prevention (CDC), de 2000 [13], adotando-se, para definição dos percentis que caracterizam o estado nutricional, os seguintes intervalos [11]: IMC $<5^{\circ} \mathrm{P}$ (indicativo de baixo peso), $5^{\circ} \mathrm{P} \leq \mathrm{IMC}<85^{\circ} \mathrm{P}$ (situação de eutrofia) e IMC $\geq 85^{\circ} \mathrm{P}$ (indicativo de excesso de peso).

As informações relativas às condições socioeconômicas da família (renda familiar, número de moradores no domicílio, escolaridade da responsável do gênero feminino pela criança, número de equipamentos/eletrodomésticos disponíveis no domicílio) foram obtidas junto aos pais/responsáveis pelos escolares por meio de questionário, que foi entregue aos alunos, no ambiente escolar, com orientações concomitantes para que fosse encaminhado aos pais/responsáveis e devolvido na escola para a equipe responsável pela pesquisa, em data pré-agendada. As análises envolvendo as variáveis socioeconômicas foram elaboradas com base nos questionários devolvidos, que corresponderam a $75,3 \%(n=244)$ do total inicial da amostra.

Além da renda familiar per capita e da escolaridade materna, empregou-se, para avaliação do nível socioeconômico das famílias dos alunos, o Critério de Classificação Econômica Brasil, adotado pela Associação Brasileira de Empresas de Pesquisa - ABEP [14]. Este critério consiste na atribuição de pontos a determinados itens de bens materiais disponíveis no domicílio, somados à escolaridade do chefe da família, categorizando-se os alunos como pertencentes às classes econômicas $\mathrm{A} 1$ (de maior nível econômico), A2, B1, B2, C, D, e E (de menor nível socioeconômico).

O tratamento estatístico foi realizado com o auxílio do software Statistical Analysis System - SAS [15], empregando-se testes de qui-quadrado comum, que possibilitam a identificação da existência de associação entre as variáveis selecionadas. Para a avaliação da convivência dos serviços escolares também se realizou análise de correlação de Spearman, envolvendo as variáveis adesão e freqüência de adesão ao PAE e à cantina. Adotou-se o nível de significância estatística de 5\%.

\section{Resultados e discussão}

A adesão média ao PAE de Campinas (SP) foi de 75\%. Entretanto, avaliando-se a freqüência de consumo das refeições distribuídas pelo programa, apenas $38,3 \%$ dos alunos participavam do PAE sistematicamente (entre quatro e cinco dias por semana). Proporção de $15,7 \%$ dos estudantes aderia ao programa três vezes por semana, $21 \%$ faziam esporadicamente (entre um e dois dias por semana) e $25 \%$ não consumiam as refeições distribuídas gratuitamente.

Partindo-se da premissa de que a adesão dos alunos ao PAE está condicionada, em grande parte, pela qualidade das refeições distribuídas pelo programa [16], foi solicitada a opinião dos alunos que participavam do PAE $(n=243 ; 75,0 \%)$ acerca das preparações presentes nos cardápios do programa (Tabelas 1 a 3). É importante registrar que apenas $0,4 \%$ dos escolares $(n=1)$ mencionaram não apreciar todas as preparações distribuídas pelo PAE, sendo este resultado somado à categoria "não gosta de algumas preparações", na apresentação das referidas tabelas.

Predominaram $(n=161 ; 66,3 \%)$ aqueles escolares que afirmaram não apreciar algumas preparações distribuídas pelo PAE (Tabela 1), sendo que destes a maioria $(57,1 \%)$ aderia esporadicamente (entre 1 e 3 dias por semana) ao programa. Nota-se que a aceitação das preparações do cardápio pelos alunos é um importante determinante da freqüência de adesão ao PAE, e o investimento na reformulação dos cardápios, com base no atendimento das preferências dos escolares, pode representar uma das estratégias eficazes na tentativa de ampliar a adesão ao programa. 
Tabela 1 - Distribuição dos alunos de acordo com a opinião acerca das preparações distribuídas pelo Programa de Alimentação Escolar e a freqüência de adesão ao programa. Campinas, 2004.

\begin{tabular}{|c|c|c|c|c|c|c|}
\hline \multirow{3}{*}{ Opinião dos alunos } & \multicolumn{4}{|c|}{$\begin{array}{c}\text { Freqüuência de adesão ao PAE } \\
\text { (em dias/semana) }\end{array}$} & \multirow{2}{*}{\multicolumn{2}{|c|}{ Total de alunos }} \\
\hline & \multicolumn{2}{|c|}{$1-3$} & \multicolumn{2}{|c|}{$4-5$} & & \\
\hline & $\mathrm{N}^{\mathrm{o}}$ & $\%$ & No & $\%$ & $\mathrm{~N}^{\mathrm{o}}$ & $\%$ \\
\hline Gosta de todas as preparações & 27 & 32,9 & 55 & 67,1 & 82 & 100,0 \\
\hline Não gosta de algumas preparações & 92 & 57,1 & 69 & 42,9 & 161 & 100,0 \\
\hline Total & 119 & 49,0 & 124 & 51,0 & 243 & 100,0 \\
\hline
\end{tabular}

Nota: Análises elaboradas tendo por base os dados referentes a 243 escolares, para os quais se dispõe de informações válidas.

$\chi^{2}=12,75$, com 1 grau de liberdade, $p=0,0004$.

Todavia, o fato de $32,9 \%$ dos alunos que afirmaram apreciar todas as preparações aderirem esporadicamente ao PAE evidencia que outros aspectos também podem influenciar na participação dos alunos e devem ser avaliados para a melhoria do desempenho do programa. Entre esses aspectos, os fatores estruturais do PAE, como as condições de distribuição das refeições, no que se refere à temperatura da alimentação, a forma de distribuição, o tempo disponível para realização da refeição, o desconforto dos refeitórios, entre outros, devem ser considerados [16-19]. Brandão [7] e Sturion [20] relatam a possibilidade de rejeição voluntária ao programa, independentemente do cardápio oferecido, motivada por uma atitude geral negativa com relação ao PAE ou por constrangimento social. Deve-se considerar, também, que o fato dos alunos gostarem de todas as preparações distribuídas pelo programa pode não refletir necessariamente em adesão integral ao PAE: o aluno pode apreciar uma preparação, mas, em determinado dia, por alguma razão inerente à estrutura do programa, não possuir motivação para consumi-la.

A condição socioeconômica reduzida de parcela dos escolares, por sua vez, pode auxiliar na explicação do fato de que $42,9 \%$ dos alunos, mesmo afirmando não apreciar algumas preparações, aderiam ao PAE de maneira efetiva. Tendo por base as informações socioeconômicas fornecidas pelos pais/responsáveis pelos escolares, verificou-se que a maioria das famílias pertencia às classes $\mathrm{C}$ e $\mathrm{D}(42,3 \%$ e $33,2 \%$, respectivamente), de acordo com o Critério Brasil.

Ainda tendo por base os dados da tabela 1, maior parcela dos alunos mencionou não apreciar algumas preparações do cardápio. As preparações do tipo "prato único" foram as mais rejeitadas $(47,2 \%)$ pelos escolares, destacando-se o "macarrão primavera" (preparação com legumes) e o "macarrão com sardinha", citados por $51,3 \%$ dos estudantes. As preparações salgadas do tipo almoço não eram apreciadas por $32,3 \%$ dos alunos, merecendo destaque a refeição "arroz com ovos mexidos", mencionada por $34,6 \%$ dos estudantes. As sopas foram rejeitadas por 21,1\% dos escolares.

Pesquisas semelhantes [16,18] também têm revelado as sopas como uma das preparações menos apreciadas pelos alunos. No entanto, vários estudos [21-23] têm evidenciado que a macarronada está entre as preparações preferidas pelos escolares. Cabe destacar que as principais motivações registradas pelos alunos para a inclusão da macarronada entre os alimentos rejeitados foram a forma de preparo - cocção insuficiente e/ou a ausência de condimentos e a presença dos acompanhamentos (legumes e sardinha). Este último aspecto fornece subsídios para o estímulo à promoção da educação nutricional em sala de aula, com vistas à valorização da diversidade alimentar na composição da dieta e à formação de bons hábitos e de vivência dos conceitos aprendidos, por meio da realização de 
refeições nutritivas, atrativas e saborosas distribuídas pelo PNAE. Vale lembrar que a formação de hábitos alimentares saudáveis corresponde a um dos principais objetivos delineados no programa governamental.

Em Campinas (SP), desde 2003, atividades de educação nutricional vêm sendo desenvolvidas pela prefeitura em uma parcela das escolas [24]. É necessário que essas ações estendam-se à totalidade das unidades de ensino, abrangendo também os pais dos alunos.

Alguns estudos [25,26] indicam diferenças nas preferências dos estudantes quanto às refeições distribuídas na escola, de acordo com o grupamento etário. Na presente pesquisa, foi captada forte associação entre a opinião relativa às preparações do PAE e a idade dos alunos (Tabela 2), sendo que maior proporção $(48,8 \%)$ dos estudantes que afirmaram apreciar todas as refeições do programa pertencia ao grupamento de menor idade (inferior a 9 anos). Maior proporção $(39,1 \%)$ de alunos, com idade superior a 13 anos, mencionou não gostar de algumas preparações do cardápio.

Tabela 2 - Distribuição dos alunos de acordo com a opinião acerca das preparações do Programa de Alimentação Escolar e os estratos de idade. Campinas, 2004.

\begin{tabular}{|c|c|c|c|c|c|c|c|c|c|c|}
\hline \multirow{3}{*}{ Opinião dos alunos } & \multicolumn{8}{|c|}{ Estratos de idade (em anos) } & \multirow{2}{*}{\multicolumn{2}{|c|}{$\begin{array}{l}\text { Total de } \\
\text { alunos }\end{array}$}} \\
\hline & \multicolumn{2}{|c|}{$<9$} & \multicolumn{2}{|c|}{$9 \longmapsto 11$} & \multicolumn{2}{|c|}{$11 \longmapsto 13$} & \multicolumn{2}{|c|}{$\geq 13$} & & \\
\hline & $\mathrm{N}^{\underline{0}}$ & $\%$ & $\mathrm{~N}^{\mathrm{o}}$ & $\%$ & $\mathrm{~N}^{\mathrm{o}}$ & $\%$ & $\mathrm{~N}^{\underline{0}}$ & $\%$ & $\mathrm{~N}^{\mathrm{o}}$ & $\%$ \\
\hline $\begin{array}{l}\text { Gosta de todas as } \\
\text { preparações }\end{array}$ & 40 & 48,8 & 23 & 28,1 & 12 & 14,6 & 7 & 8,5 & 82 & 100,0 \\
\hline $\begin{array}{l}\text { Não gosta de } \\
\text { algumas preparações }\end{array}$ & 23 & 14,3 & 29 & 18,0 & 46 & 28,6 & 63 & 39,1 & 161 & 100,0 \\
\hline Total & 63 & 25,9 & 52 & 21,4 & 58 & 23,9 & 70 & 28,8 & 243 & 100,0 \\
\hline
\end{tabular}

Estudo [27] conduzido no País de Gales, envolvendo grupos focais com crianças menores ( 7 a 8 anos) e mais velhas (10 a 11 anos), visando avaliar as preferências alimentares, identificou que os alunos mais jovens revelaram maior preferência pelas refeições distribuídas na escola, justificando o fato de serem refeições quentes, com boas características sensoriais e que permitiam a socialização com os demais colegas. Além disso, as crianças mais novas expressaram preferência por refeições do tipo tradicional, ao invés daquelas do tipo lanche. Já os alunos de maior idade preferiam levar para a escola alimentos preparados no domicílio, devido, principalmente, à possibilidade de escolha dos alimentos que comporiam os lanches.

$\mathrm{Na}$ presente pesquisa, não foram observadas diferenças estatisticamente significativas $(p<0,05)$ quanto às preferências dos alunos no tocante a alguma preparação específica distribuída pelo PAE e os grupamentos etários aos quais pertenciam.

Julgou-se pertinente avaliar a distribuição da opinião dos escolares no que se refere às preparações do PAE, de acordo com os rendimentos familiares per capita (Tabela 3 ). 
Tabela 3 - Distribuição dos alunos de acordo com a opinião acerca das preparações do Programa de Alimentação Escolar e os estratos de renda familiar per capita. Campinas, 2004.

\begin{tabular}{|c|c|c|c|c|c|c|c|c|c|c|c|c|}
\hline \multirow{3}{*}{$\begin{array}{l}\text { Opinião dos } \\
\text { alunos }\end{array}$} & \multicolumn{10}{|c|}{ Estratos de renda familiar per capita (em salários mínimos) } & \multirow{2}{*}{\multicolumn{2}{|c|}{$\begin{array}{c}\text { Total de } \\
\text { alunos }\end{array}$}} \\
\hline & \multicolumn{2}{|c|}{$\leq 1 / 4$} & \multicolumn{2}{|c|}{$1 / 4-1 / 2$} & \multicolumn{2}{|c|}{$1 / 2-\mid 1$} & \multicolumn{2}{|c|}{$1-12$} & \multicolumn{2}{|c|}{$>2$} & & \\
\hline & № & $\%$ & $\mathrm{~N}^{\mathrm{o}}$ & $\%$ & $\mathrm{~N}^{\mathrm{o}}$ & $\%$ & № & $\%$ & $\mathrm{~N}^{\mathrm{o}}$ & $\%$ & № & $\%$ \\
\hline \multirow[t]{2}{*}{$\begin{array}{l}\text { Gosta de } \\
\text { todas as } \\
\text { preparações }\end{array}$} & 8 & 17,0 & 16 & 34,1 & 15 & 31,9 & 8 & 17,0 & 0 & 0,0 & 47 & 100,0 \\
\hline & & $(30,8)$ & & $(41,0)$ & & $(27,3)$ & & $(40,0)$ & & $(0,0)$ & & \\
\hline \multirow{2}{*}{$\begin{array}{l}\text { Não gosta } \\
\text { de algumas } \\
\text { preparações }\end{array}$} & 18 & 18,4 & 23 & 23,5 & 40 & 40,8 & 12 & 12,2 & 5 & 5,1 & 98 & 100,0 \\
\hline & & $(69,2)$ & & $(59,0)$ & & $(72,7)$ & & $(60,0)$ & & $(100,0)$ & & \\
\hline Total & 26 & 17,9 & 39 & 26,9 & 55 & 37,9 & 20 & 13,8 & 5 & 3,5 & 145 & 100,0 \\
\hline
\end{tabular}

Notas: Análises elaboradas tendo por base os dados referentes a 145 escolares, para os quais se dispõe de informações válidas.

Os números entre parênteses são os percentuais em relação aos valores (totais) observados nas colunas.

$\chi^{2}=4,94$, com 4 graus de liberdade, $p=0,2936$.

Não foram captadas diferenças estatisticamente significativas $(p<0,05)$ entre as opiniões dos alunos acerca das preparações distribuídas pelo PAE em função dos rendimentos familiares (Tabela 3). Mesmo entre os escolares pertencentes a famílias com menores rendimentos per capita (até um quarto do salário mínimo), maior parcela $(69,2 \%)$ afirmou não apreciar algumas preparações distribuídas pelo PAE.

É interessante notar que, embora a aceitação das preparações pelos alunos não tenha apresentado associação com a renda familiar, a adesão e a freqüência de adesão dos escolares ao PAE estiveram condicionadas a fatores socioeconômicos, avaliados por meio da renda familiar per capita e do Critério de Classificação Econômica Brasil. Adotando-se este último critério, verificou-se que a adesão ao PAE foi de 92,9\% entre os alunos pertencentes à classe econômica $\mathrm{E}$, proporção que praticamente reflete a universalidade, decrescendo com o aumento dos rendimentos familiares e alcançando metade dos escolares pertencentes à classe econômica mais elevada
(A2) na amostra $\left(\chi^{2}=17,14\right.$, com 5 graus de liberdade, $p=0,0042)$.

A freqüência de adesão ao PAE também se revelou inversamente associada $\left(\chi^{2}=49,91\right.$, com 25 graus de liberdade, $p=0,0022)$ às classes econômicas, sendo que o consumo diário das refeições distribuídas pelo programa foi maior entre os alunos pertencentes às menores classes de rendimentos (E, $D$ e C). Dessa forma, enquanto $42,9 \%$ dos escolares da classe E aderiam diariamente ao PAE, entre os escolares, cujas famílias recebiam maiores rendimentos, a participação diária no programa foi nula. A maioria dos estudantes das classes B1 e B2 $(75,7 \%$ e $83,3 \%$, respectivamente) aderia ao programa esporadicamente (até dois dias por semana).

Nota-se, portanto, que mesmo não apreciando algumas preparações dos cardápios, parcela dos alunos, de maneira particular aquela formada pelas famílias com menores rendimentos, aderia ao PAE. Tal situação reflete, possivelmente, a escassez de recursos desses alunos para a aquisição de 
alimentos nas cantinas escolares ou em outros locais no entorno das unidades de ensino ou, ainda, para levar alimentos do domicílio como lanche, sendo as refeições distribuídas gratuitamente pelo PAE a principal opção para que esses estudantes se mantenham alimentados durante a jornada de aulas. O presente estudo confirma, desse modo, a importância que o PAE assume, especialmente para os alunos classificados como relativamente mais pobres. Já os alunos pertencentes a famílias com maiores rendimentos apresentam maiores oportunidades de escolha, como, por exemplo, a aquisição de alimentos, quando as refeições distribuídas pelo PAE não atendem às suas expectativas. Cabe destacar, que a alimentação escolar deve ser vista como um recurso para manter o estudante alimentado durante a jornada de aulas, independentemente de sua condição socioeconômica [28].

Visando ampliar a aceitabilidade às refeições do cardápio do PAE e a adesão dos estudantes ao programa, torna-se fundamental a análise das preferências alimentares dos escolares. Solicitou-se ao aluno que escolhesse, entre doze opções préestabelecidas, cinco refeições que compusessem um cardápio do Programa de Alimentação Escolar. Merece destaque que, como primeira opção, proporções semelhantes de estudantes indicaram preferir uma refeição mais completa, do tipo almoço $(30,3 \%)$, ou uma refeição do tipo lanche com suco $(27,1 \%)$. Menores parcelas de alunos $(16,4 \%$ e $15,4 \%)$ optaram pelas preparações doces e do tipo lanche com leite, respectivamente. Sobre as refeições do tipo prato único e as sopas recaíram as menores proporções de preferência dos escolares $(8,0 \%$ e $2,8 \%$, respectivamente).

No entanto, avaliando-se a freqüência total citada para as preparações, observou-se a preferência dos alunos por refeições do tipo lanche com suco $(21,4 \%)$ ou com leite $(21,1 \%)$, seguidas das preparações doces $(19,4 \%)$, do tipo almoço $(15,9 \%)$, prato único $(15,8 \%)$ e das sopas $(6,4 \%)$.

No município de Campinas, no período da presente pesquisa, 13,3\% dos cardápios das escolas pesquisadas eram compostos por refeições mais completas do tipo almoço, 30\% por lanches com leite, 6,7\% por lanches com suco e a maior proporção $(50 \%)$ por refeições salgadas do tipo prato único. Nota-se que estas últimas preparações (do tipo prato único) estiveram entre as menos selecionadas pelos escolares como preferidas para compor o cardápio do PAE.

Sturion [20], avaliando os cardápios semanais planejados para o PNAE em vinte unidades de dez municípios brasileiros, verificou que, do total de refeições, a maior proporção $(43,8 \%)$ era composta por preparações salgadas sólidas do tipo prato único, que apresentavam características de refeição principal e não de um lanche, como seria, de acordo com a referida autora, o esperado para este tipo de programa.

A questão envolvendo o tipo de preparação mais adequado (refeições mais completas, com características de almoço, ou preparações consideradas mais leves, do tipo lanche) a ser distribuído pelo PNAE vem sendo discutida intensamente há anos, e envolve, entre outros fatores, a análise das características do público beneficiário e de infra-estrutura para a execução do programa em cada localidade.

Em muitos municípios são disponibilizadas, com freqüência, preparações salgadas mais completas, do tipo almoço, justificando-se, para tanto, o nível socioeconômico da população que tradicionalmente se beneficia do programa (alunos relativamente mais pobres) [29]. Mas, há argumentos em torno da distribuição de preparações mais leves, como lanches saudáveis e sucos, devido ao horário que as refeições são servidas (período matutino ou vespertino) [30]. No município de Campinas (SP), os cardápios são diferenciados de acordo com a região na qual a unidade de ensino está localizada, sendo disponibilizadas refeições consideradas mais completas, no tocante ao conteúdo nutricional, para alunos matriculados em áreas menos favorecidas economicamente. Portanto, os cardápios não se diferenciam em função do horário de distribuição das refeições [24].

É importante registrar que na presente pesquisa não foram observadas diferenças 
estatisticamente significativas $\quad(p<0,05)$ quando foram consideradas as preferências dos escolares por preparações específicas e os rendimentos familiares ou a idade dos alunos.

Porém, verificou-se associação $\left(\chi^{2}=\right.$

28,82 , com 10 graus de liberdade, $p=0,0013$ ) quando se analisou as preferências dos estudantes pelas preparações dos cardápios apresentados no momento das entrevistas, de acordo com o horário no qual os escolares participavam do PAE. Maior proporção de alunos $(46,8 \%)$, que aderia ao programa no período vespertino, preferia os cardápios do tipo lanche (com leite ou suco), em comparação com aqueles do período matutino $(38,8 \%)$. Os maiores percentuais de preferência pelas preparações do tipo almoço foram registrados entre os alunos que participavam do PAE no período intermediário $(35,1 \%)$ - no qual as refeições são servidas às 12:30 horas - ou vespertino $(32,5 \%)$. As preparações doces foram preferidas $(52,8 \%)$ pelos escolares que recebiam as refeições do PAE no período matutino, sendo menos aceitas $(13,2 \%)$ pelos alunos do período intermediário.

Não há dúvidas de que a inclusão de um alimento e/ou preparação no cardápio deve ser planejada levando-se em consideração o horário de distribuição, o clima da região, a faixa etária do público alvo, os hábitos alimentares dos beneficiários, a vocação agrícola de cada localidade, além dos recursos disponíveis [3,4].

No que se refere ao atendimento dos hábitos alimentares até 1991, o cardápio do PAE de Campinas era composto exclusivamente por alimentos formulados (produtos de rápido preparo e fácil estocagem e distribuição, como enlatados, sopas e bebidas lácteas), que apresentavam como desvantagens o custo elevado e a reduzida aceitação entre os escolares. A partir de 1991, os produtos in natura começaram a ser incorporados ao programa. Contudo, até 1997, os formulados ainda representavam a maior parte dos gêneros distribuídos, tornando os cardápios monótonos [7,8,31]. Uma das possíveis vantagens que vem sendo apontada pelos defensores do modelo de gestão compartilhado, implementado desde 2001, é a possibilidade de maior introdução de produtos in natura nos cardápios, favorecida pela parceria da Secretaria da Educação com a CEASA do município. Em 2003, do rol de produtos adquiridos para o programa, 31\% representavam o grupo das carnes e $29 \%$ das frutas e hortaliças [9].

Por meio do presente estudo foi possível identificar que, tendo por base os cardápios das escolas visitadas, no período relativo à pesquisa, seu planejamento priorizava os produtos semi-elaborados e in natura. Tal situação representa melhorias na composição dos cardápios no que se refere à substituição dos alimentos formulados. Enfatiza-se a necessidade de avaliação de outros aspectos, como a variedade das receitas, as distintas combinações de ingredientes, a forma de preparo e de apresentação dos alimentos e preparações, a fim de ampliar a aceitação das refeições entre os alunos.

Além da distribuição das refeições do programa de alimentação escolar, em metade das unidades de ensino pesquisadas encontravam-se disponíveis os serviços das cantinas. Os resultados descritos a seguir referem-se, portanto, aos dados dos alunos ( $n$ = 163) que freqüentavam as unidades que mantinham as cantinas escolares. Proporção de $76,1 \%$ dos estudantes afirmou adquirir alimentos comercializados por este tipo de estabelecimento. Analisando-se a freqüência de consumo na cantina, $21,5 \%$ dos alunos aderiam efetivamente (entre quatro e cinco dias por semana), $14,7 \%$ aderiam três vezes por semana, $39,3 \%$ adquiriam alimentos esporadicamente (entre um e dois dias por semana) e $24,5 \%$ não aderiam à cantina em nenhum dia da semana.

Não foi observada associação estatisticamente significativa $(p<0,05)$ entre as variáveis idade e adesão (ou frequiência de adesão) à cantina. Quando se analisou a aquisição de alimentos nas cantinas em função do gênero dos alunos, foi captada associação $\left(\chi^{2}=20,85\right.$, com 1 grau de liberdade, $p<0,0001)$ entre as variáveis, sendo que maior proporção de meninas $(69,4 \%)$ consumia alimentos adquiridos nestes estabelecimentos, em comparação com os meninos $(30,6 \%)$. A 
adesão mais efetiva à cantina (entre quatro e cinco dias por semana) era realizada por $27,8 \%$ das meninas e $12,1 \%$ dos meninos, sendo as diferenças de consumo entre os gêneros estatisticamente significativas $\left(\chi^{2}=\right.$ 26,63, com 5 graus de liberdade, $p<0,0001$ ).

No entanto, avaliando-se a adesão à cantina em função do gênero e do estado nutricional dos alunos, não foram captadas diferenças estatisticamente significativas $(p<0,05)$ entre as variáveis, ou seja, não foi constatado que as meninas que apresentavam maior prevalência de excesso de peso adquiriam mais freqüentemente alimentos da cantina.

Analisando-se a adesão à cantina de acordo com a condição socioeconômica das famílias dos escolares, avaliada por meio da renda familiar per capita, verificou-se que as variáveis consideradas estavam diretamente associadas $\left(\chi^{2}=16,28\right.$, com 4 graus de liberdade, $p=0,0027)$. Dessa forma, enquanto $35,7 \%$ dos escolares pertencentes a famílias com menor renda per capita (de até um quarto de salário mínimo) afirmaram que aderiam à cantina, 91,7\% dos alunos das famílias com maiores rendimentos (acima de dois salários) adquiriam alimentos desse estabelecimento. $\mathrm{O}$ mesmo comportamento é observado quando se analisa a freqüência de adesão à cantina em função dos rendimentos familiares per capita (Tabela 4).

Tabela 4 - Distribuição dos alunos de acordo com a freqüência de adesão à cantina escolar e os estratos de renda familiar per capita (em salários mínimos). Campinas, 2004.

\begin{tabular}{|c|c|c|c|c|c|c|c|c|c|c|}
\hline \multirow{3}{*}{$\begin{array}{l}\text { Estratos de } \\
\text { renda } \\
\text { familiar } \\
\text { per capita }\end{array}$} & \multicolumn{8}{|c|}{ Freqüência (dias/semana) de adesão à cantina escolar } & \multicolumn{2}{|c|}{ Total de alunos } \\
\hline & \multicolumn{2}{|c|}{0} & \multicolumn{2}{|c|}{$1-2$} & \multicolumn{2}{|c|}{3} & \multicolumn{2}{|c|}{$4-5$} & \multirow[b]{2}{*}{$\mathrm{N}^{\mathrm{o}}$} & \multirow[b]{2}{*}{$\%$} \\
\hline & $\mathrm{N}^{\mathrm{o}}$ & $\%$ & $\mathrm{~N}^{\mathrm{o}}$ & $\%$ & $\mathrm{~N}^{\mathrm{o}}$ & $\%$ & $\mathrm{~N}^{\mathrm{o}}$ & $\%$ & & \\
\hline$\leq 1 / 4$ & 9 & 64,3 & 3 & 21,4 & 1 & 7,2 & 1 & 7,1 & 14 & 100,0 \\
\hline $1 / 4-1 / 2$ & 5 & 21,7 & 8 & 34,8 & 6 & 26,1 & 4 & 17,4 & 23 & 100,0 \\
\hline $1 / 2-1$ & 7 & 21,2 & 13 & 39,4 & 7 & 21,2 & 6 & 18,2 & 33 & 100,0 \\
\hline $1-12$ & 2 & 10,5 & 9 & 47,4 & 3 & 15,8 & 5 & 26,3 & 19 & 100,0 \\
\hline$>2$ & 1 & 8,3 & 2 & 16,7 & 4 & 33,3 & 5 & 41,7 & 12 & 100,0 \\
\hline Total & 24 & 23,8 & 35 & 34,6 & 21 & 20,8 & 21 & 20,8 & 101 & 100,0 \\
\hline
\end{tabular}

Nota: Análises elaboradas tendo por base os dados referentes a 101 escolares, para os quais se dispõe de informações válidas.

$\chi^{2}=22,32$, com 12 graus de liberdade, $p=0,0341$.

Não foi possível verificar associação, na presente pesquisa, entre a adesão dos alunos às cantinas escolares quando foram consideradas as variáveis escolaridade materna $\left(\chi^{2}=3,76\right.$, com 4 graus de liberdade, $p=0,4390)$ e estado nutricional do escolar $\left(\chi^{2}\right.$ $=0,68$, com 3 graus de liberdade, $p=0,8775$ ) .

As tabelas 5 e 6 reúnem os dados relativos à convivência dos dois serviços de alimentação - o Programa de Alimentação
Escolar e as cantinas - disponíveis nas unidades de ensino. Cabe lembrar que estas análises foram elaboradas com base no número total de estudantes $(n=163)$ matriculados nas escolas que contavam com estes dois tipos de serviços $(n=3)$ e que integravam a amostra do presente estudo. 
Tabela 5 - Distribuição dos alunos de acordo com a adesão ao Programa de Alimentação Escolar e a adesão à cantina escolar. Campinas, 2004.

\begin{tabular}{|c|c|c|c|c|c|c|}
\hline \multirow{3}{*}{ Adesão ao PAE } & \multicolumn{4}{|c|}{ Adesão à cantina escolar } & \multirow{2}{*}{\multicolumn{2}{|c|}{ Total de alunos }} \\
\hline & \multicolumn{2}{|c|}{ Sim } & \multicolumn{2}{|c|}{ Não } & & \\
\hline & $\mathrm{N}^{\mathrm{o}}$ & $\%$ & $\mathrm{~N}^{\mathrm{o}}$ & $\%$ & $\mathrm{~N}^{\mathrm{o}}$ & $\%$ \\
\hline Sim & 77 & 72,0 & 30 & 28,0 & 107 & 100,0 \\
\hline Não & 47 & 83,9 & 9 & 16,1 & 56 & 100,0 \\
\hline Total & 124 & 76,1 & 39 & 23,9 & 163 & 100,0 \\
\hline
\end{tabular}

Nota: Análises elaboradas tendo por base os dados referentes a 163 escolares, para os quais se dispõe de informações válidas.

$\chi^{2}=2,89$, com 1 grau de liberdade, $p=0,0890$.

Entre os alunos (Tabela 5) que aderiam à alimentação distribuída pelo PAE $(n=107 ; 65,6 \%), 72 \%$ também afirmaram consumir os alimentos da cantina escolar. Esta situação indica que os estudantes podem tanto realizar uma possível complementaridade entre as refeições distribuídas pelo PAE e os alimentos adquiridos na cantina, quanto a substituição da adesão a um serviço por outro, dependendo da freqüência de adesão dos alunos aos serviços (análise apresentada na sequiência do artigo). Entre os alunos que não consumiam a alimentação escolar $(n=56$; $34,4 \%)$, expressivo contingente $(83,9 \%)$ adquiria alimentos das cantinas. Tal condição indica a substituição das refeições distribuídas pelo PAE pelos alimentos comercializados pelas cantinas.

Ainda tendo por base os dados da tabela 5, não foram captadas diferenças estatisticamente significativas $(p<0,05)$ entre a proporção de alunos que afirmou aderir ao PAE e aquela que não participava do programa, em função da adesão à cantina. Nota-se=que para esta análise se considerou apenas a adesão, representando a participação dos alunos nos serviços escolares, independentemente do número de dias por semana (freqüência de adesão) que os alunos aderiam ao PAE ou à cantina.
Analisando-se a frequiência de adesão aos dois serviços de alimentação (Tabela 6), verificou-se que conforme crescia a freqüência de adesão ao PAE, reduzia-se a frequiência de adesão à cantina. Dessa forma, 87,2\% dos alunos que, efetivamente, aderiam ao PAE (entre quatro e cinco dias por semana) adquiriam alimentos da cantina esporadicamente (até dois dias por semana). De forma inversa, entre os escolares cuja adesão à cantina pode ser classificada como efetiva (quatro e cinco dias por semana), a maioria $(54,3 \%)$ não participava do PAE. Estes resultados indicam a substituição da adesão a um serviço por outro. É necessário que o PAE seja reconhecido e priorizado pelo aluno como a opção para a alimentação no intervalo das atividades escolares. Para tanto, é fundamental, como pré-requisito na tentativa de ampliar a participação dos escolares no PAE, que o programa seja bem estruturado e que especial atenção seja dedicada à elaboração dos cardápios. Cabe lembrar que, além da valorização dos cardápios, outros fatores podem contribuir para ampliar a adesão dos alunos ao programa, como a educação nutricional e o estímulo familiar para o consumo das preparações distribuídas gratuitamente pelo PAE. 
Tabela 6 - Distribuição dos alunos de acordo com a freqüência de adesão ao Programa de Alimentação Escolar e a freqüência de adesão à cantina escolar. Campinas, 2004.

\begin{tabular}{|c|c|c|c|c|c|c|c|c|c|c|}
\hline \multirow{3}{*}{$\begin{array}{l}\text { Frequiência } \\
\text { (dias/semana) } \\
\text { de adesão ao } \\
\text { PAE }\end{array}$} & \multicolumn{8}{|c|}{ Freqüência (dias/semana) de adesão à cantina escolar } & \multirow{2}{*}{\multicolumn{2}{|c|}{ Total de alunos }} \\
\hline & \multicolumn{2}{|c|}{0} & \multicolumn{2}{|c|}{$1-2$} & \multicolumn{2}{|c|}{3} & \multicolumn{2}{|c|}{$4-5$} & & \\
\hline & № & $\%$ & № & $\%$ & № & $\%$ & № & $\%$ & № & $\%$ \\
\hline \multirow[t]{2}{*}{0} & 9 & 16,1 & 14 & 25,0 & 14 & 25,0 & 19 & 33,9 & 56 & 100,0 \\
\hline & & $(22,5)$ & & $(21,9)$ & & $(58,3)$ & & $(54,3)$ & & \\
\hline \multirow[t]{2}{*}{$1-2$} & 6 & 16,7 & 16 & 44,4 & 6 & 16,7 & 8 & 22,2 & 36 & 100,0 \\
\hline & & $(15,0)$ & & $(25,0)$ & & $(25,0)$ & & $(22,8)$ & & \\
\hline \multirow[t]{2}{*}{3} & 7 & 29,2 & 11 & 45,8 & 1 & 4,2 & 5 & 20,8 & 24 & 100,0 \\
\hline & & $(17,5)$ & & $(17,2)$ & & $(4,2)$ & & $(14,3)$ & & \\
\hline \multirow[t]{2}{*}{$4-5$} & 18 & 38,3 & 23 & 48,9 & 3 & 6,4 & 3 & 6,4 & 47 & 100,0 \\
\hline & & $(45,0)$ & & $(35,9)$ & & $(12,5)$ & & $(8,6)$ & & \\
\hline Total & 40 & 24,5 & 64 & 39,3 & 24 & 14,7 & 35 & 21,5 & 163 & 100,0 \\
\hline
\end{tabular}

Por outro lado, $37,8 \%$ dos alunos que participavam do PAE, com uma freqüência igual ou superior a três dias por semana, também afirmaram adquirir alimentos nas cantinas com uma frequiência de no mínimo três vezes por semana. Esta situação demonstra que parcela dos alunos fazia uso concomitante dos serviços escolares.

As análises de correlação entre os serviços disponíveis no ambiente escolar corroboraram os resultados registrados nas tabelas 5 e 6 . Verificou-se uma correlação igual a $-0,13(p=0,0901)$ quando se considerou apenas a adesão ao PAE e à cantina, e um coeficiente de $-0,35(p<0,0001)$ avaliando-se a frequiência de adesão aos serviços escolares.

Integrava o instrumento adotado nas entrevistas junto aos alunos, uma questão que solicitava ao escolar que selecionasse, entre as opções pré-estabelecidas, as motivações para a aquisição de alimentos na cantina ou em outros locais, como lanchonetes localizadas no entorno da unidade de ensino, para serem consumidos durante a jornada de aula. Com base nas respostas dos estudantes, elaborou-se a tabela 7, cujos resultados auxiliam a compreensão sobre as opções dos alunos para o consumo de alimentos no âmbito escolar.

Expressiva parcela dos estudantes $(47,1 \%)$ aderia à cantina mesmo quando consumia a refeição escolar, resultado que apresenta concordância com o descrito na tabela 6. É importante considerar que as aquisições na cantina podem variar desde um alimento que complemente a alimentação escolar, como exemplo um suco de frutas, quando esta é considerada insuficiente pelo aluno, ou ainda, daqueles classificados como "guloseimas", como doces, refrigerantes, salgadinhos industrializados, entre outros. 
Tabela 7 - Distribuição dos alunos de acordo com as motivações para aquisição de alimentos nas cantinas escolares ou em outros locais. Campinas, 2004.

\begin{tabular}{lrrrr}
\hline \multirow{2}{*}{ Motivações } & \multicolumn{4}{c}{ Opção dos alunos } \\
\cline { 2 - 5 } & \multicolumn{3}{c}{ Sim } & \multicolumn{3}{c}{ Não } \\
\cline { 2 - 5 } & $\mathrm{N}^{\mathbf{0}}$ & \multicolumn{1}{c}{$\%$} & \multicolumn{1}{c}{$\%$} \\
\hline Mesmo quando consome a merenda, compra na cantina & 80 & 47,1 & 90 & 52,9 \\
Quando não gosta da merenda oferecida no dia & 54 & 31,8 & 116 & 68,2 \\
Quando não consome a merenda oferecida na escola & 27 & 15,9 & 143 & 84,1 \\
Quando não traz lanche de casa & 11 & 6,5 & 159 & 93,5 \\
\hline
\end{tabular}

Notas: - Respostas não excludentes.

- Análises elaboradas tendo por base os dados referentes a 170 escolares, para os quais se dispõe de informações válidas.

Proporção de $31,8 \%$ dos escolares optava pela compra na cantina quando não apreciava as preparações distribuídas pelo Programa de Alimentação Escolar. Resultados semelhantes foram observados por Sturion et al. [32] por meio de análise de dados de amostra $(n=402)$ de alunos do município de Piracicaba (SP). Os autores verificaram associação inversa entre o consumo de merenda escolar e a freqüência de aquisição dos alimentos comercializados pelas cantinas. Praticamente a metade dos alunos revelou adquirir alimentos nas cantinas (ou em locais próximos às unidades de ensino, para consumo no intervalo das atividades escolares) mesmo quando optava pelo consumo das refeições distribuídas pelo Programa de Alimentação Escolar, sendo que $31 \%$ dos estudantes afirmaram que este comportamento era adotado quando as preparações não atendiam às suas preferências e expectativas.

Tal situação reafirma a importância da avaliação dos cardápios do programa, incorporando, na medida do possível, alimentos e preparações balanceados nutricionalmente, que atendam às preferências dos alunos e que sejam economicamente sustentáveis.

Ainda de acordo com a tabela 7, chama a atenção, também, que $68,2 \%$ dos alunos que não consumiam a alimentação escolar distribuída no dia não se motivavam para a aquisição de alimentos nas cantinas escolares ou em outros locais. Tal situação pode ser justificada, provavelmente, pelo reduzido nível socioeconômico de parcela dos alunos integrantes da amostra.

Para 22,4\% dos escolares, a cantina representava uma opção para a alimentação, visto que estes alunos não consumiam as refeições distribuídas pelo $\mathrm{PAE}$ ou não possuíam o hábito de levar para a escola os lanches preparados no domicílio. No entanto, é importante destacar que a maioria dos alimentos comercializados pelas cantinas escolares possui, freqüentemente, elevado teor de energia, gorduras, açúcares e/ou sódio.

Por meio da análise das citações dos alunos de Campinas (SP), quanto aos alimentos mais adquiridos nas cantinas, pôdese constatar que a preferência dos escolares recaía sobre os produtos ricos em açúcares e energia, sendo a bala o alimento mais citado $(66,4 \%)$, seguida pelo salgadinho do tipo chips $(49,2 \%)$, doces $(45,1 \%)$, salgado do tipo caseiro $(44,3 \%)$, refrigerante $(41,8 \%)$ e chocolate $(19,7 \%)$. Alimentos como sucos, lanche natural e bolo foram citados por pequena parcela dos alunos $(3,3 \%, 4,1 \%$ e $2,5 \%$, respectivamente).

No que diz respeito à aquisição de alimentos em outros locais, nas imediações da unidade de ensino, para consumo no intervalo das atividades escolares, $44,4 \%$ dos alunos ( $n$ = 144) adotavam a referida prática, sendo os mercados/supermercados $(39,8 \%)$ e os bares $(31,3 \%)$ os principais locais mencionados. Entre os alimentos adquiridos merecem destaque o salgadinho do tipo chips $(62,5 \%)$, biscoitos $(41,7 \%)$, balas $(36,1 \%)$, chicletes $(19,4 \%)$ e refrigerantes $(16 \%)$.

A maioria dos alunos $(n=67 ; 55,8 \%)$ afirmou gastar valores diários iguais ou 
superiores a R\$ 5,00 com a compra de alimentos na cantina escolar (média de $\mathrm{R} \$$ 4,86; desvio padrão $-\mathrm{dp}=2,18$ ). $\mathrm{O}$ dispêndio médio diário com a aquisição de alimentos em outros locais para serem consumidos na escola totalizou $\mathrm{R} \$ 4,00(\mathrm{dp}=2,50)$.

Caroba [33] e Warwick et al. [34] registraram que, ao dispor de autonomia para a aquisição de alimentos no ambiente escolar, as escolhas dos alunos nem sempre são as mais adequadas do ponto de vista nutricional. A praticidade, a rapidez, a influência do grupo de amigos e as características sensoriais são fatores que contribuem para a aquisição dos alimentos comercializados pelas cantinas ou por bares/lanchonetes no entorno das escolas.

Warren et al. [27] relatam que na ausência do controle familiar em relação ao alimento que deve ser consumido, as crianças tendem a fazer escolhas menos saudáveis, ingerindo maior quantidade de alimentos ricos em gorduras e açúcares, como os snacks.

Deve-se considerar que as cantinas escolares, bem como os locais que vendem alimentos no entorno das unidades de ensino, operando em contexto comercial e na ausência de fiscalização das normas vigentes, comercializam com freqüência aqueles produtos, geralmente bastante divulgados pela mídia, que são reconhecidos como os preferidos pelos estudantes. $\mathrm{O}$ desafio enfrentado é fazer com que as escolhas favoritas dos alunos sejam também as mais saudáveis $[35,36]$.

Pode-se perceber a importância de incluir o tema alimentação e nutrição nas discussões em sala de aula, reconhecendo a escola como espaço propício para a consolidação de bons hábitos e para o desenvolvimento de atitudes perante as diferentes questões relativas à saúde.

No entanto, alguns estudos [34,35] revelaram que o fato da criança/adolescente reconhecer um alimento como "bom" ou "ruim" do ponto de vista nutricional (por exemplo, alimentos ricos em gordura ou açúcar são ruins e os que contêm fibras são bons) não se constituiu em motivação relevante que influenciasse as escolhas alimentares no ambiente escolar, principalmente devido ao fato dos alunos não estarem preparados para abandonar o consumo dos alimentos preferidos.

Noble et al. [35] destacam que para a eficácia das atividades de educação nutricional é necessário ir além da idéia de "bom" ou "saudável", "ruim" ou "não saudável" e promover o conceito de equilíbrio alimentar, auxiliando as crianças a fazerem escolhas que forneçam uma ingestão adequada de energia e nutrientes e um balanço apropriado de alimentos ricos em gorduras ou açúcares. Assim, os alimentos preferidos pelos alunos nas cantinas ou no entorno das unidades de ensino, que apresentam usualmente reduzido valor nutricional, não precisam ser proibidos na alimentação, mas podem ser escolhidos com menor freqüência para integrar a dieta.

Tem sido reconhecido também que, para que as crianças sejam guiadas em direção a escolhas alimentares adequadas nos lanches escolares, os responsáveis pelos serviços de alimentação disponíveis nas unidades de ensino e aqueles envolvidos com a educação nutricional devem trabalhar de forma conjunta [35]. Edmonds et al. [37] destacam que o ambiente físico que cerca a criança/adolescente pode facilitar ou limitar os esforços para a manutenção das práticas alimentares. Escolhas alimentares mais saudáveis devem estar disponíveis no meio em que o aluno se encontra, para que este tenha condições de manter hábitos adequados.

Ressalta-se a necessidade de valorização da alimentação distribuída pelo PAE, como uma refeição balanceada elaborada de forma a suprir parcela das necessidades nutricionais do escolar. Diversas estratégias de encorajamento do consumo de alimentos saudáveis nas unidades de ensino podem ser promovidas: o professor consumindo a merenda escolar e expressando satisfação; o estímulo para que a criança prove um alimento distribuído pelo PAE; o oferecimento de opções de escolha dentro de um mesmo grupo de alimentos; as condições ambientais favoráveis nos refeitórios, permitindo a socialização dos alunos [38].

Além disso, a regulamentação do comércio de alimentos pelas cantinas (por meio de portarias específicas) também se torna importante, para o oferecimento de opções que 80 
possibilitem escolhas alimentares mais adequadas do ponto de vista nutricional.

A Portaria Interministerial $\mathrm{N}^{\mathrm{o}} 1.010$ [39] destaca a necessidade de fomentar mudanças sócio-ambientais, em nível coletivo, para o favorecimento de escolhas individuais saudáveis. A referida Portaria instituiu, em maio de 2006, as diretrizes para a promoção da alimentação saudável nas escolas das redes pública e particular de ensino infantil, fundamental e médio. Entre os eixos prioritários definidos, merecem destaque: a promoção das ações de educação alimentar e nutricional, o estímulo à implantação de boas práticas de manipulação de alimentos para os serviços disponíveis no ambiente escolar, a restrição nas escolas ao comércio de alimentos com elevado teor de açúcares, gorduras e sal e o incentivo ao consumo de frutas e hortaliças, bem como o monitoramento do estado nutricional dos escolares. É necessário, portanto, a adequação das cantinas às diretrizes governamentais estabelecidas, com vistas ao oferecimento de opções mais saudáveis para o consumo nos lanches escolares.

Pesquisa [36] conduzida no Reino Unido com os responsáveis $(n=244)$ pelas refeições distribuídas nas unidades de ensino revelou que mais de $70 \%$ acreditavam influenciar, de alguma forma, as escolhas alimentares dos alunos, enquanto cerca de 90\% acreditavam desempenhar papel no fornecimento de alimentos para uma dieta saudável. As principais restrições apresentadas para o oferecimento de escolhas mais adequadas do ponto de vista nutricional foram as características sensoriais e o custo desses produtos. Além disso, os resultados indicaram que a opinião dos pais, quando comparada à dos alunos, exerceu maior influência sobre os responsáveis pelas refeições escolares no que se refere à possibilidade de oferecer escolhas mais saudáveis. Os responsáveis pelas refeições nas escolas britânicas que haviam participado de cursos, relacionados ao conteúdo nutricional dos alimentos, apresentaram, significativamente, maior probabilidade de tentar fornecer opções mais saudáveis aos estudantes. Estes resultados demonstram a importância da participação dos pais nas atividades escolares dos filhos, particularmente naquelas relacionadas à alimentação e nutrição, bem como a necessidade de propiciar cursos de treinamento para os responsáveis pelo oferecimento de alimentos/refeições no ambiente escolar.

\section{Conclusões}

Os resultados obtidos evidenciam que o atendimento das preferências dos alunos associa-se, positivamente, com a frequiência de adesão ao Programa de Alimentação Escolar PAE, representando um importante aspecto que deve ser considerado no momento da elaboração dos cardápios. Espera-se que as análises implementadas, no que se refere aos diferentes aspectos associados às preferências alimentares dos alunos, constituam-se em subsídios para os gestores do PAE, para a melhoria do programa governamental.

Além da análise das preferências quanto às preparações do $\mathrm{PAE}$, recomendamse estudos que avaliem a influência das condições estruturais do programa (tais como as características de distribuição da merenda escolar) na adesão dos alunos e na aceitabilidade às refeições distribuídas pelo PAE.

No que se refere à convivência dos serviços de alimentação no ambiente escolar, verificou-se, por meio de fatores como a adesão, freqüência de adesão e valores despendidos pelos estudantes com as aquisições, que as cantinas são vistas pelos alunos como importante local para a compra de alimentos, seja em substituição às refeições distribuídas gratuitamente pelo PAE ou em complementação a estas. É necessário o desenvolvimento de programas de orientação nutricional que enfoquem a importância de uma dieta equilibrada, valorizando as refeições distribuídas pelo PAE, e preparando o estudante para a realização de escolhas alimentares conscientes.

É fundamental, também, que as cantinas ofereçam opções mais saudáveis para o lanche escolar. Neste sentido, a regulamentação do comércio de alimentos 
pelas cantinas (por meio de portarias específicas) pode estimular o oferecimento de alimentos com menor teor de açúcares, gorduras e/ou sódio, representando uma medida importante em direção à escola como local facilitador de escolhas alimentares saudáveis.
Considera-se que os instrumentos desenvolvidos para a realização da pesquisa conseguiram captar os diferentes aspectos pretendidos, apresentando, além disso, linguagem compatível com o entendimento dos alunos.

\section{Agradecimentos}

Os autores agradecem ao Conselho Nacional de Desenvolvimento Científico e Tecnológico - CNPq pelos recursos disponibilizados para a implementação da pesquisa, por meio do processo № 504369/2003-2, e à Coordenação de Aperfeiçoamento de Pessoal de Nível Superior - CAPES pela concessão de bolsa de mestrado à primeira autora.

\section{Referências Bibliográficas}

1. Gambardella AMD, Frutuoso MFP, Franch C. Prática alimentar de adolescentes. Rev Nutr. 1999; 12(1): 55-63.

2. Danelon MAS, Danelon MS, Silva MV da. Serviços de alimentação destinados ao público escolar: análise da convivência do Programa de Alimentação Escolar e das cantinas. Segurança Alimentar e Nutricional. 2006; 13(1): 85-94.

3. Brasil. Ministério da Educação. Fundo Nacional de Desenvolvimento da Educação [Internet] [acesso em 2007 maio 04]. Resolução № 32, de 10 de agosto de 2006. Estabelece as normas para a execução do Programa Nacional de Alimentação Escolar PNAE. Disponível em: http://www.fnde.gov.br/.

4. Weis B, Chaim NA, Belik W. Manual de gestão eficiente da merenda escolar. 2 ed. São Paulo: Margraf; 2005. 82 p.

5. Brasil. Ministério da Educação. Fundo Nacional de Desenvolvimento da Educação FNDE. Alimentação escolar. 2007. [Internet] [acesso em 2007 maio 04]. Disponível em: http://www.fnde.gov.br/home/index.jsp?arqui vo=/alimentação_escolar/alimenta

cao_esc.html.

6. Silva JG, Belik W, Takagi M (coord.). Projeto Fome Zero: uma proposta de política de segurança alimentar para o Brasil. São Paulo: Instituto Cidadania; 2001.
7. Brandão TM. Avaliação da aceitação e preferência dos cardápios do Programa de Merenda Escolar em escolas municipais do ensino fundamental da cidade de Campinas [dissertação]. Campinas: Universidade Estadual de Campinas; 2000. 91 p.

8. Nogueira RM. O Programa Nacional de Alimentação Escolar como uma política pública: o caso de Campinas - SP [dissertação]. Campinas: Universidade Estadual de Campinas; 2004. 155 p.

9. Carmo M. Programa de alimentação escolar de Campinas recebe prêmio nacional. 2004. [Internet] [acesso em 2007 jun 05]. Disponível em: http://www.campinas.sp. gov.br/noticias.

10. Instituto Nacional de Estudos e Pesquisas Educacionais Anísio Teixeira - INEP. Censo Educacional 2004. [Internet] [acesso em 2005 out 15]. Disponível em: http://www.inep.gov.br.

11. World Health Organization - WHO. Physical status: the use and interpretation of anthropometry. Geneva: WHO; 1995. (Technical Report Series, n. 854).

12. Center for Disease Control and Prevention - CDC. Epi-Info. Epidemiology Program Office [computer program]. Version 3.3.2. Atlanta; Georgia: Division of Public Health Surveillance Informatics; 2000.

13. Center for Disease Control and Prevention - CDC. 2000 CDC Growth Charts for The United States: Methods and Development. Atlanta: CDC; 2002. 190 p. (Vital and Health Statistics - Series 11, n. 246). 
14. Associação Brasileira de Empresas de Pesquisa - ABEP. Critério de Classificação Econômica Brasil. 2003. [Internet] [acesso em 2007 abr 24]. Disponível em: http://www.abep.org.

15. Sas Institute Inc. The Statistical Analysis System [computer program]. Version 8.2. Cary: SAS Institute Inc.; 2000.

16. Muniz VM, Carvalho AT de. O Programa Nacional de Alimentação Escolar em município do Estado da Paraíba: um estudo sob o olhar dos beneficiários do Programa. Rev Nutr. 2007; 20(3): 285-96.

17. Panciera AL, Sturion GL, Silva MV da. Subsídios para a gestão do Programa de Alimentação Escolar. In: Anais eletrônicos do $6^{\circ}$ Simpósio Latino-Americano de Ciência de Alimentos; 2005 nov 7-10; Campinas, São Paulo: Simpósio Latino-Americano de Ciência de Alimentos; 2005.

18. Martins R de CB, Medeiros MAT de, Ragonha GM, Olbi JH, Segatti MEP, Osele MR. Aceitabilidade da alimentação escolar no ensino público fundamental. Saúde em Revista. 2004; 6(13): 71-8.

19. Abreu M. Alimentação escolar: combate à desnutrição e ao fracasso escolar ou direito da criança e ato pedagógico. Em aberto. 1995; 15(67): 5-20.

20. Sturion GL. Programa de alimentação escolar: avaliação do desempenho em dez municípios brasileiros [tese]. Campinas: Universidade Estadual de Campinas; 2002. $269 \mathrm{p}$.

21. Flávio EF. Alimentação escolar e avaliação nutricional dos alunos do ensino fundamental das escolas municipais de Lavras, MG [tese]. Lavras: Universidade Federal de Lavras; 2006. 293 p.

22. Brasil. Ministério da Educação. Fundo Nacional de Desenvolvimento da Educação. Avaliação do impacto distributivo e elaboração de sistemática de monitoramento do PNAE. 2002. [Internet] [acesso em 2003 set 04]. Disponível em: http://www.fnde.gov.br/apresentacoes/apresen tacao01/index.html.

23. Carvalho LMF de. Preferências alimentares de crianças e adolescentes matriculados no ensino fundamental da rede pública da cidade de Bauru: uma análise de fatores ambientais no estudo da obesidade [dissertação]. Ribeirão Preto: Universidade de São Paulo; 2005. 96 p.

24. Portes L. Programa de educação alimentar leva a boa refeição às escolas de Campinas. 2006. [Internet] [acesso em 2007 jun 05]. Disponível em: http://www. campinas.sp.gov.br/noticias.

25. Oetterer M, Silva MV da, Ometto AMH, Pipitone MAP, Furtuoso MCO, Sturion GL. Avaliação do programa de alimentação escolar: projeto FNDCT (FINEP) - BID. Piracicaba: ESALQ/USP; 1999. 365 p.

26. Stolarski MC. Caminhos da alimentação escolar no Brasil: análise de uma política pública no período de 2003-2004 [dissertação]. Curitiba: Universidade Federal do Paraná; 2005. 160 p.

27. Warren E, Parry O, Linch R, Murphy S. 'If I don't like it then I can choose what I want': Welsh schoolchildren's accounts of preference for and control over food choice. Health Promot Int. 2008; 23(2): 144-51.

28. Moyses MAA, Collares CAL. Aprofundando a discussão das relações entre desnutrição, fracasso escolar e merenda. Em aberto. 1995; 15(67): 33-56.

29. Danelon, MAS. Modelos de gestão do Programa de Alimentação Escolar: a experiência aplicada às unidades de tempo integral [dissertação]. Piracicaba: Universidade de São Paulo; 2007. 233 p.

30. Pecorari $\mathrm{R}$ de CF. Uma proposta de inovação no cardápio escolar baseada na avaliação do Programa de Alimentação Escolar, de Piracicaba - SP [dissertação]. Araraquara: Universidade Estadual Paulista "Júlio de Mesquita Filho"; 2006. 167p.

31. Vianna RPT, Tereso MJA. Análise do programa de merenda escolar em Campinas. Cad Debate. 1997; 5: 46-76.

32. Sturion GL, Panciera AL, Silva MV da. Alimentação escolar: opções de consumo na unidade de ensino. In: Anais eletrônicos do $6^{\circ}$ Simpósio Latino-Americano de Ciência de Alimentos, 2005 nov 7-10; Campinas, São Paulo: Simpósio Latino-Americano de Ciência de Alimentos; 2005.

33. Caroba, DCR. A escola e o consumo alimentar de adolescentes matriculados na rede pública de ensino [dissertação]. 
Piracicaba: Universidade de São Paulo; 2002. $162 \mathrm{p}$.

34. Warwick J, McIlveen H, Strugnell C. Meal preferences amongst 9 to 15-year-old Ulster schoolchildren. Appetite. 1997; 28: 86.

35. Noble C, Corney M, Eves A, Kipps M, Lumbers M. School meals: primary schoolchildren's perceptions of the healthiness of foods served at school and their preferences for these foods. Health Education Journal. 2001; 60(2): 102-19.

36. Eves A, Corney M, Kipps M, Noble C, Lumbers M, Price M. The nutritional implications of food choices from catering outlets. Nutrition \& Food Science. 1996; 5: 26-9.

37. Edmonds J, Baranowski T, Baranowski J, Cullen KW, Myres D. Ecological and socioeconomic correlates of fruit, juice and vegetable consumption among AfricanAmerican boys. Prev Med. 2001; 32: 476-81. 38. Bizzo MLG, Leder L. Educação nutricional nos parâmetros curriculares nacionais para o ensino fundamental. Rev Nutr. 2005; 18(5): 661-7.

39. Brasil. Ministério da Saúde; Ministério da Educação. [Internet] [acesso em 2007 maio 04]. Portaria Interministerial № 1.010 , de 08 de maio de 2006. Institui as diretrizes para a promoção da alimentação saudável nas escolas de educação infantil, fundamental e nível médio das redes públicas e privadas, em âmbito nacional. Disponível em: http://www.fnde.gov.br/.

\section{Autores:}

Mariana Schievano Danelon - Mestre em Ciência e Tecnologia de Alimentos pelo Departamento de Agroindústria, Alimentos e Nutrição da "Escola Superior de Agricultura Luiz de Queiroz" - ESALQ/USP.

Correspondência: Rua MMDC, 167, Jaraguá, Piracicaba/SP, CEP: 13401-320.

Telefone: (19) 3422-4854. E-mail: mariana.danelon@ig.com.br

Maria Conceição Pereira da Fonseca - Docente do Instituto Multidisciplinar em Saúde - IMS, Campus Anísio Teixeira/UFBA

Marina Vieira da Silva - Professora Doutora do Departamento de Agroindústria, Alimentos e Nutrição da "Escola Superior de Agricultura Luiz de Queiroz" - ESALQ/USP.

Enviado em: 12/03/2008

Recebido em: 28/07/2008 